\title{
Schisandrin B elicits the Keap I-Nrf2 defense system via carbene reactive metabolite which is less harmful to mice liver
}

This article was published in the following Dove Press journal: Drug Design, Development and Therapy

\author{
Shan Feng* \\ Bingxun Qiu* \\ Li Zou \\ Ke Liu \\ Xiaoyu Xu \\ Huifeng Zhu \\ College of Pharmaceutical Sciences \\ and Chinese Medicine, Southwest \\ University, Beibei, Chongqing 4007I5, \\ China \\ *These authors contributed equally \\ to this work
}

Correspondence: Xiaoyu Xu; Huifeng Zhu

College of Pharmaceutical Sciences and Chinese Medicine, Southwest University, Beibei, 2 Tiansheng Road, Chongqing 4007I5, China

Tel/fax +86 236825 I225 zhfbsci@I26.com
Email xuxiaoyu@swu.edu.cn;

Background: Schisandrin B (Sch B) a main active component of Schisandra chinensis, has been shown to act as a liver protectant via activation of the Nrf2 pathway. Nevertheless, it remains unclear whether its reactive metabolite is responsible for Nrf2 activation; also, the effects of its reactive metabolite on liver function are still unknown.

Methods: The present study determined and identifed the carbene reactive metabolite of Sch $\mathrm{B}$ in human and mice liver microsomes. Its roles in activating Nrf2 pathway and modifying macromolecules were further explored in human liver microsomes. Moreover the potential cytotoxicity and hepatoxicity of carbene on HepG-2 and mice were also investigated.

Results: In the present study, cytochromes P450 (CYP450s) metabolized Sch B to carbene reactive metabolite, which, with the potential to modify peptides, were identifed and observed in human and mice liver microsomes. Moreover, the relevance of carbene in Nrf2 activation was verifed by coincubation in the presence of CYP450 inhibitors in HepG-2 cells, as well as by molecular docking study of carbene and Keap1. Additionally, the cytotoxicity of Sch B on HepG-2 cells was signifcantly aggravated by CYP450 inducer (with $\mathrm{LD}_{50}$ decreasing from 63 to $21 \mu \mathrm{M}$ ) and signifcantly alleviated by CYP450 inhibitor and glutathione (with $\mathrm{LD}_{50}$ increasing from $63 \mu \mathrm{M}$ to $200 \mu \mathrm{M}$ ). Besides, after oral administration of mice with Sch B (25-100 mg/kg) for 21 days, only the highest dose induced mild hepatotoxicity, which was accompanied by increasing the aminotransferase activity and centrilobular hepatocellular infltration of lymphocytes. In addition, upregulation of CYP450 activity; Nrf2, NQO-1, and GST expression; and glutathione level was observed in Sch B treatment groups.

Conclusion: The present study revealed that CYP450s mediate the conversion of Sch B to carbene, which subsequently binds to Keap1 and elicits Nrf2 pathway, which could further increase the elimination of carbene and thus exhibit a less harmful effect on mice liver.

Keywords: Schisandra chinensis, schisandrin B, CYP450s, carbene reactive metabolite, hepatotoxicity, Nrf2

\section{Introduction}

Schisandrin B (Sch B) is the most abundant and the most active isolated dibenzocyclooctadiene derivative found in the fruit of Schisandra chinensis (Turcz.) Baill. It is a well-known Chinese medicinal herb commonly prescribed for the treatment of viral and chemical hepatitis. Modern pharmacological researches have demonstrated its antioxidant, anti-inflammatory, cardioprotective, hepatoprotective, neuroprotective, and renoprotective effects. ${ }^{1-4}$ These effects can be attributed to activation of nuclear factor erythroid 2-related factor 2 (Nrf2) pathway, which is an important transcription factor for protecting cells against oxidative damage. For example, Sch B has been shown to protect AML12 hepatocytes against apoptosis by activating ERK/Nrf2, ${ }^{5}$ promoting antiinflammatory effects by modulating both Nrf2 and NF-kB in lymphocytes, ${ }^{6}$ decreasing Sy
hereby accept the Terms. Non-commercial uses of the work are permitted without Conmy further permission from Dove Medical Press Limited, provided the work is properly attributed. For permission

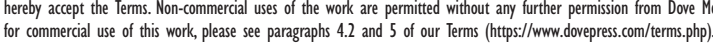


benzo $(a)$ pyrene-induced human trophoblast HTR-8/SVneo cell damage via activation of Nrf2-ARE pathway, ${ }^{7}$ and inhibiting lipopolysaccharide-induced inflammatory response in human umbilical vein endothelial cells by activating Nrf2 in vitro. ${ }^{8}$ Similarly, Sch B showed a neuroprotective effect in 6-hydroxydopamine-induced Parkinson's disease in vivo by activating $\mathrm{Nrf} 2$ pathway, ${ }^{3}$ decreasing $\mathrm{CCl}_{4}$-induced liver fibrosis in rats by regulating Nrf2-ARE signaling pathways, ${ }^{9}$ and protecting cigarette smoke-induced airway injury in mice through Nrf2 pathway. ${ }^{10}$ However, the exact mechanism by which Sch B activates Nrf2 pathway remains unclear. Some studies have suggested that the activation of Nrf2 signal pathway is mediated by the interaction between the CYP450s and Sch B. Chen et al have demonstrated that reactive oxygen species arising from the CYP-catalyzed metabolism of $(-)$ Sch B elicit the glutathione antioxidant system. ${ }^{11}$ Furthermore, Leong et al have proved that 1-aminobenzotriazolea (ABT, a known nonspecific CYP450s inhibitor) completely suppresses the (-) Sch B-induced Nrf2 activation, which further supports the involvement of a CYP-catalyzed reaction in the activation process. ${ }^{5,12}$ Nevertheless, the exact components of reactive oxygen species remain unknown.

According to Fontana et al, there are eleven common substructures which generate reactive metabolites through CYP metabolism: terminal (w) and w-1 acetylenes, furans and thiophenes, epoxides, dichloro- and trichloro-ethylenes, secondary amines, benzodioxoles (methylenedioxyphenyl compounds), isothiocyanates, thioamides, dithiocarbamates, conjugated structures, and terminal alkenes. ${ }^{13}$ In addition, analysis of Sch B revealed that it contains a benzodioxole structure (Figure 1A), which is believed to form a carbene reactive metabolite via CYP450s (Figure 1B). ${ }^{13}$ Therefore, we speculated that the carbene reactive metabolite could be the reactive oxygen species produced from Sch B via CYP450s.

The present study determined and identified the carbene reactive metabolite of Sch $\mathrm{B}$ in human and mice

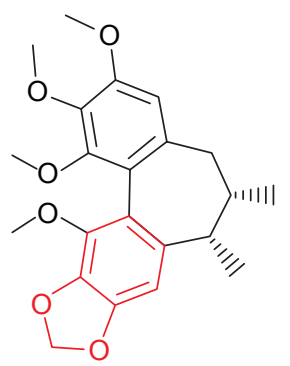

A

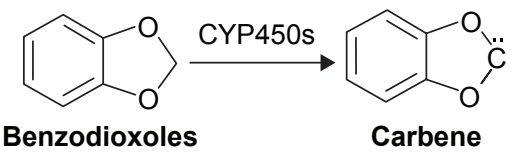

B
Figure I The structure of Sch B (A) and the route of benzodixoles in forming carbene reactive metabolite $(\mathbf{B})$. liver microsomes. Its roles in activating Nrf2 pathway and modifying macromolecules were further explored. Moreover, the potential cytotoxicity and hepatoxicity of carbene on HepG-2 and mice were also investigated. Taken together, the present study elucidates the pros and cons of Sch B as a therapeutic agent.

\section{Materials and methods Chemicals and reagents}

Sch B, phenobarbital sodium, and carbamazepine were provided by the National Institute for the Control of Pharmaceutical and Biological Products (Beijing, China). Phenacetin, paracetamol, tolbutamide, 4-hydroxytolbutamide, dextromethorphan, dextrorphan, chlorzoxazone, 6-hydroxychlorzoxazone, midazolam, 1-hydroxymidazolam, and $\beta$-nicotinamide adenine dinucleotide phosphate (NADPH) were purchased from Sigma-Aldrich Co. (St Louis, MO, USA). Mice liver microsomes and human liver microsomes were purchased from the Research Institute for Liver Diseases Co., Ltd (Shanghai, China). LC-MS grade methanol, ethanol, and acetonitrile were obtained from Thermo Fisher Scientific, Inc. (Waltham, MA, USA). All other regents were of analytical grade.

\section{Characterization of reactive metabolites of Sch B in mice and human liver microsomes}

Sch B at $50 \mu \mathrm{M}$ was incubated for 120 minutes at $37^{\circ} \mathrm{C}$ with mice or human liver microsomes in $100 \mathrm{mM}$ phosphate buffer $(\mathrm{pH} 7.4)$ in the presence of NADPH $(2 \mathrm{mM})$ and glutathione (GSH, $5 \mathrm{mM}$ ). Control incubations in the absence of Sch B or presence of ABT were conducted. The protein concentration of liver microsomes used in the incubation was $1 \mathrm{mg} / \mathrm{mL}$. The total incubation volume was $1 \mathrm{~mL}$. Incubation samples were quenched with twofold volume of iced methanol and followed by centrifugation. The supernatant was transferred for ultra-performance liquid chromatography-tandem mass spectrometery (UPLC-MS/MS) analysis to conduct reactive metabolite profiling (detailed in the following section).

The UPLC-MS/MS method was conducted using a Waters Acquity UPLC Sample Manager and a Waters Acquity UPLC Binary Solvent Manager connected to a Waters Q-TOF mass spectrometer equipped with a combined electrospray ion (ESI) probe and Mass Lynx 1.4 software (Waters, Milford, MA, USA). An Acquity UPLC HSS C18 column $\left(1.8 \mu \mathrm{m}, 2.1 \times 100 \mathrm{~mm}^{2}\right)$ was used. Instrument settings were as follows: ESI+; source temperature, $150^{\circ} \mathrm{C}$; desolvation temperature, $450^{\circ} \mathrm{C}$; capillary voltage, $3.0 \mathrm{kV}$; desolvation $\mathrm{N}_{2}, 800 \mathrm{~L} / \mathrm{h}$; cone $\mathrm{N}_{2}, 50 \mathrm{~L} / \mathrm{h}$. The data acquisition was 
carried out at m/z 100-1,000 Da in the total ion scan mode. The MS/MS spectra were acquired at m/z 50-600 Da in the daughter ion scan mode. The solvent system consisted of solvent $\mathrm{A}\left(0.1 \% \mathrm{CH}_{3} \mathrm{COOH}\right)$ and solvent $\mathrm{B}$ (acetonitrile containing $0.1 \%$ formic acid). The high-performance liquid chromatography (HPLC) separation used a linear gradient program of $50 \%-80 \%$ B for 9 minutes, $80 \%-100 \%$ B for 2 minutes, $100 \%$ B for 2 minutes, $100 \%-50 \%$ B for 1 minute, and $50 \% \mathrm{~B}$ for 1 minute. The flow rate was $0.4 \mathrm{~mL} / \mathrm{min}$.

\section{Molecular docking study of carbene reactive metabolite to Keap I}

Molecular docking study was performed to investigate the binding mode between the carbene and the human Kelchlike ECH-associated protein 1 (Keap1) using Autodockvina 1.1.2. ${ }^{14}$ The three-dimensional (3D) structure of the human Keap1 was downloaded from Protein Data Bank (http:// www.rcsb.org/pdb/home/home.do). The 3D structure of the carbene was drawn by Chem Bio Draw Ultra 14.0 and ChemBio3D Ultra 14.0 software (PerkinElmer Inc., Waltham, MA, US). The Auto Dock Tools 1.5.6 package was employed to generate the docking input files. ${ }^{15,16}$ The search grid of Keap1 was identified as center_x: -24.826 , center_y: -3.883 , and center_z: 9.505 with dimensions, size_x: 15, size_y: 15, and size_z: 15. The value of exhaustiveness was set to 20 . For Vina docking, the default parameters were used if not otherwise specified. The best scoring pose as judged by the Vina docking score was chosen and visually analyzed using PyMoL 1.7.6 software (http://www.pymol.org/).

\section{Identification of modified peptides and corresponding microsomal proteins in} human liver microsomes treated with Sch B

Shotgun proteomics combining two MS-compatible solubilization approaches was applied to detect/identify modified peptides and corresponding proteins in human liver microsomes incubated with Sch B. The incubation and sample processing were done according to the previously reported methodology. ${ }^{17}$ Briefly, Sch B at $50 \mu \mathrm{M}$ was incubated for 120 minutes at $37^{\circ} \mathrm{C}$ with human liver microsomes in $100 \mathrm{mM}$ phosphate buffer $(\mathrm{pH} 7.4)$ in the presence (or absence) of NADPH (2 mM). The protein concentration of liver microsomes used in the incubation was $1 \mathrm{mg} / \mathrm{mL}$. The total incubation volume was $1 \mathrm{~mL}$. After incubation, samples were ultracentrifuged at $100,000 \times g$ for 1 hour. The microsome pellets were then resuspended in $25 \mu \mathrm{L}$ of trifluoroethanol. The resuspended samples were solubilized at $50^{\circ} \mathrm{C}$ for 60 minutes. Consequently, the proteins were alkylated with iodacetamide at a final concentration of $10 \mathrm{mM}$ at room temperature in the dark for 30 minutes. Trypsin digestion was carried out using sequencing-grade modified trypsin 1:25 (trypsin-to-protein ratio w/w) at $37^{\circ} \mathrm{C}$ overnight. Digested samples were stored at $-80^{\circ} \mathrm{C}$ until liquid chromatographytandem mass spectrometry (LC-MS/MS) analysis (detailed in the following section).

All digested samples were analyzed using an Accela HPLC system coupled to a Q Exactive mass spectrometer (Thermo Fisher Scientific). The injection volume was $50 \mu \mathrm{L}$, which corresponded to $10 \mu \mathrm{g}$ of starting proteins. Chromatographic separations were performed with an Acclaim PepMap RSLC C18, $5 \mu \mathrm{m}(2.1 \times 100 \mathrm{~mm})$ column at a flow rate of $0.3 \mathrm{~mL} / \mathrm{min}$. The column was eluted with water containing $0.1 \%$ formic acid (solvent $\mathrm{A}$ ) and acetonitrile containing $0.1 \%$ formic acid (solvent B). The HPLC separation used a linear gradient program of $5 \%$ B for 5 minutes, $5 \%-90 \%$ B for 50 minutes, $90 \%$ B for 5 minutes, $90 \%-5 \%$ B for 3 minutes, and 5\% B for 2 minutes. The Q Exactive MS was operated in the positive ion electrospray mode using nitrogen as the sheath and auxiliary gases. The heated capillary temperature was set at $400^{\circ} \mathrm{C}$, the capillary voltage was $27 \mathrm{~V}$, the source voltage was $4.5 \mathrm{kV}$, and the tube lens voltage was $150 \mathrm{~V}$. The acquisition cycle consisted of a full scan with a mass range from $\mathrm{m} / \mathrm{z} 350$ to 1,800 at the resolution of 70,000. Then the MS/MS scans with top 20 peaks were performed with the resolution of 17,500 , the maximum ion time of $60 \mathrm{~ms}$, and the AGC target of 1e5.

The original files from mass spectrometry were processed and transformed by MM File Conversion software on the instrument, and after the MGF files were obtained, the ProteinPilot software (AB Sciex, Framingham, MA, USA) was used to retrieve them. The parameters were as follows: fixed modifications: carbamidomethyl $(\mathrm{C})$; variable modifications: oxidation (M); enzyme: trypsin; maximum missed cleavages: 2; level one error in mass spectrometry (peptide mass tolerance): $20 \mathrm{ppm}$; level 2 error in mass spectrometry (fragment mass tolerance): $0.6 \mathrm{Da}$; mass number of peptide/fragment ions (mass values): monoisotopic; significance threshold: 0.05 .

\section{Effects of Sch B on HepG-2 viability and mice liver function}

\section{Cell culture and treatment}

HepG-2 cells were purchased from Beijing zhongyuan Ltd. (Beijing, China). The HepG-2 cells were seeded in 96-well plates at a density of 10,000 cells/well, and then cultured in RPMI 1640 medium with 10\% FBS for 12 hours before 
treatment. Twelve hours after seeding, cells were pretreated with ABT (0.5 mM) for 4 hours, phenobarbital sodium (Phen, $20 \mu \mathrm{M}$ ) for 24 hours, and GSH (5.0 mM) for 4 hours, respectively. Consequently, cells were exposed to Sch B $(5,25,100$, and $200 \mu \mathrm{M})$ alone or in combination with ABT/ Phen/GSH for 48 hours. At the end of the experiment, the content of lactate dehydrogenase (LDH) in the supernatant and the survival of the cells were determined using the commercial kits produced by Nanjing Jiancheng Bioengineering Institute (Jiangsu, China).

The effects of ABT on the ability of Sch B to activate the Nrf2 signal pathway were further evaluated in HepG-2 cells. Briefly, 12 hours after seeding, cells were exposed to Sch B $(5 \mu \mathrm{M})$ alone or in combination with ABT $(0.5 \mathrm{mM})$ for 48 hours. After that, cell extracts were prepared for Western blot analysis.

\section{Animal experiments}

KunMing (KM) male mice (18-22 g) were purchased from the Experimental Animal Center, Chongqing Medical University (Chongqing, China). All mice were kept under a standard 12-hour dark/light cycle with water and food provided ad libitum. All procedures (including the mice euthanasia procedure) were done in compliance with the regulations and guidelines of Chongqing Medical University Institutional Animal Care and Use Committee and conducted according to the AAALAC and the IACUC guidelines. ${ }^{36,37}$ Besides, the animal experiment project was approved by the Ethics Committee Board of College of Pharmaceutical Sciences in Southwest University.

Mice were randomly divided into four groups: untreated control group, Sch B 25.0, 50.0, 100 mg/kg-treated groups; Sch B was administered once per day (orally, dissolved in $0.5 \%$ sodium carboxymethylcellulose solution) for a total of 21 days. All mice were sacrificed 24 hours after administration of the last dose. Prior to proceeding with euthanasia, blood was collected from each mouse and livers were removed, snap frozen in liquid nitrogen, and stored at $-80^{\circ} \mathrm{C}$ for further analysis. In addition, most studies considered 80 $\mathrm{mg} / \mathrm{kg} \mathrm{Sch} \mathrm{B}$ as an organ protectant in animal studies, 3,9,10,18,19 and hence the present study conducted animal experiments with 25-100 mg/kg Sch B.

\section{Histologic and biochemical assessment}

Liver tissues fixed in neutral buffered formalin were embedded in paraffin, cut into $5 \mu \mathrm{m}$-thick sections, and stained with H\&E according to a standard protocol. Serum alanine aminotransferase, aspartate aminotransferase, and alkaline phosphatase activities were determined with a commercial assay kit on a Beckman Synchron CX5 Clinical System (Beckman Coulter, Inc., Indianapolis, IN, USA). GSH levels in liver were assessed using commercially available kits.

\section{Western blot analysis and immunofluorescence}

Liver extracts were prepared from frozen liver tissues, and protein concentration was determined using the Bradford method. Equivalent amounts of protein extracts were subjected to SDS-PAGE and then blotted onto polyvinylidene fluoride membranes (EMD Millipore, Bedford, MA, USA). Proteins were blocked with 5\% nonfat milk in Tris-buffered saline. Membranes were then incubated with primary antibodies (antiNrf2, anti-HO-1, anti-NQO1, anti-GST, anti-GR [Abcam, Cambridge, UK]) at $4^{\circ} \mathrm{C}$ overnight, followed by the incubation with the secondary antibody conjugated with horseradish peroxidase at room temperature for 1 hour. Protein-antibody complexes were detected using an electro-chemiluminescence kit (Engreen Bio system, Beijing, China) and exposed to an X-ray film (GE Healthcare, Piscataway, NJ, USA).

Liver sections embedded in paraffin were cut into $10 \mu \mathrm{m}$ thick sections. Sections were incubated with $3 \% \mathrm{H}_{2} \mathrm{O}_{2}$ in methanol for 10 minutes, followed by blocking with $1 \%$ bovine serum albumin in PBS for 30 minutes and incubating at $37^{\circ} \mathrm{C}$. Next, sections were incubated at $4^{\circ} \mathrm{C}$ overnight with a primary antibody against TUNEL (1:300), followed by incubation with Alexa-Fluor488/594 donkey anti-rabbit secondary antibody (1:500; Thermo Fisher Scientific) for 1 hour at $37^{\circ} \mathrm{C}$. After that, the cell nucleus was stained with DAPI. Images were captured on a Zeiss fluorescence microscope (Carl Zeiss, Mainz, Germany).

\section{Microsomal CYP450 activity detection}

Microsomes were isolated from the mice livers $(\sim 2 \mathrm{~g})$. Briefly, the liver samples were homogenized with $3 \times$ volumes of potassium phosphate buffer $(\mathrm{pH} 7.4)$ containing EDTA $(1.0 \mathrm{mM})$ and sucrose $(250 \mathrm{mM})$. The homogenate was centrifuged at $9,000 \times g$ for 20 minutes. The supernatant was then centrifuged at $100,000 \times g$ for 60 minutes. Finally, the precipitate was resuspended in $100 \mathrm{mM}$ potassium phosphate buffer ( $\mathrm{pH}$ 7.4) containing $250 \mathrm{mM}$ glycerol and stored at $80^{\circ} \mathrm{C}$ before use. The temperature was kept at $4^{\circ} \mathrm{C}$ during the whole period of preparation, and all solutions were stored at $4{ }^{\circ} \mathrm{C}$ before use. Protein concentrations of the prepared microsomes were calculated using the Bradford assay method with bovine serum albumin as the standard.

Incubation was done according to the previously described approach. ${ }^{20}$ The incubation mixtures $(200 \mu \mathrm{L})$ included $100 \mathrm{mM}$ potassium phosphate buffer ( $\mathrm{pH}$ 7.4), 
$0.5 \mathrm{mg} / \mathrm{mL}$ mice microsomal protein, and mixture probe substrates for CYP450s (10 $\mu \mathrm{M}$ phenacetin for CYP1A2, $100 \mu \mathrm{M}$ tolbutamide for CYP2C19, $2.5 \mu \mathrm{M}$ dextromethorphan for CYP2D6, $20 \mu \mathrm{M}$ chlorzoxazonefor CYP2E1, 5 $\mu \mathrm{M}$ midazolam for CYP3A4). The reaction was initiated by addition of $1 \mathrm{mM}$ NADPH and was terminated by adding $400 \mu \mathrm{L}$ iced methanol (containing the internal standard of carbamazepine, $75 \mathrm{ng} / \mathrm{mL}$ ) 30 minutes post-incubation. After centrifugation $(5,000 \times g, 10$ minutes $)$, the organic phase was separated and dried with nitrogen. The residues were dissolved in $200 \mu \mathrm{L}$ of methanol and water (50:50, v/v) and centrifuged at $10,000 \times g$ for 5 minutes. A $10 \mu \mathrm{L}$ aliquot of supernatant was injected for determination of the metabolites of five CYP450 probe substrates by LC-MS/MS (detailed in the following section).

In our previous study, we have reported a rapid LC-MS/ MS method for determination of the activities of five CYP450s in the rat liver. ${ }^{20}$ Briefly, the HPLC system consisted of an LC-20 AD pump, a DGU-20 A3 degasser, a SIL20AC autosampler, and a CTO-20A column oven (Shimadzu, Kyoto, Japan). The separation was performed on an Agilent ZORBAX XDB-C18 column $(50 \times 2.1 \mathrm{~mm} \times 3.5 \mu \mathrm{m}$; Agilent Technologies, Santa Clara, CA, USA). The flow rate was $0.45 \mathrm{~mL} / \mathrm{min}$ and consisted of water with $0.1 \%$ formic acid (A) and methanol with $0.1 \%$ formic acid (B) using a gradient elution (0.0-0.5 minutes, $98 \% \mathrm{~A}$; 0.5-1.0 minute, from $98 \%$ A to $2 \% \mathrm{~A} ; 1.0-2.5$ minutes, $2 \% \mathrm{~A} ; 2.5-2.51$ minutes, from $2 \%$ A to $98 \%$ A; $2.51-4.0$ minutes, $98 \%$ A). An API 4000 Q trap mass spectrometer (Applied Biosystems, Foster
City, CA, USA) equipped with an ESI source was used for mass analysis and detection. Following optimization of the setting parameters, the ESI source was operated in both the positive mode for paracetamol, 4-hydroxytolbutamide, dextrorphan, 1-hydroxymidazolam, and carbamazepine, and the negative mode for 6-hydroxychlorzoxazone with the curtain, nebulizer, and turbo-gas (all nitrogen) set at 15, 60, and $55 \mathrm{psi}$, respectively. The source temperature was $550^{\circ} \mathrm{C}$, and the ion spray needle voltage was $5,000 \mathrm{~V}$ in the positive mode and $-4,200 \mathrm{~V}$ in the negative mode. For detailed method validation results, please refer to a previous study. ${ }^{20}$

\section{Statistical analysis}

Data are expressed as the mean \pm SD. To determine statistically significant differences between groups, two-tailed unpaired Student's $t$-test and one-way ANOVA were carried out using SPSS 19.0 statistical software. $P<0.05$ was considered statistically significant.

\section{Results}

\section{Formation of carbene reactive metabolite from Sch B in mice and human liver microsomes}

The rationale for the identification of carbene reactive metabolite lies in the trapping of reactive metabolites with a nucleophile (GSH, $5 \mathrm{mM}$ ). UPLC-MS/MS analyses of the incubation mixture indicated that there was only one GSH conjugate $\left([\mathrm{M}+\mathrm{H}]^{+}, \mathrm{m} / \mathrm{z} 688, \mathrm{t}_{\mathrm{R}}=3.16\right.$ minutes $)$ formed (Figure $2 \mathrm{~A}$ and $\mathrm{B}$ ) in mice or human incubation mixture.
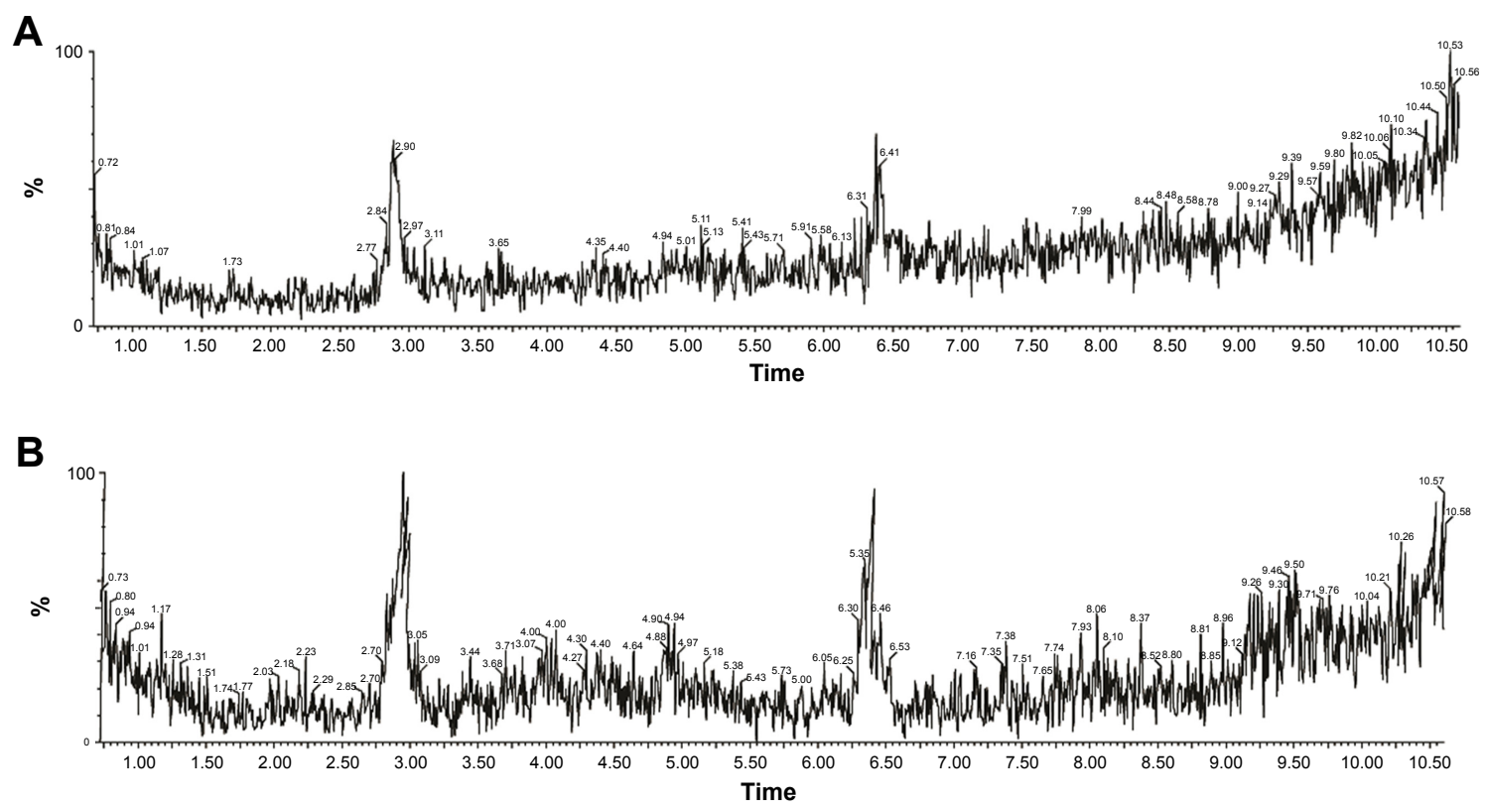

Figure 2 (Continued) 

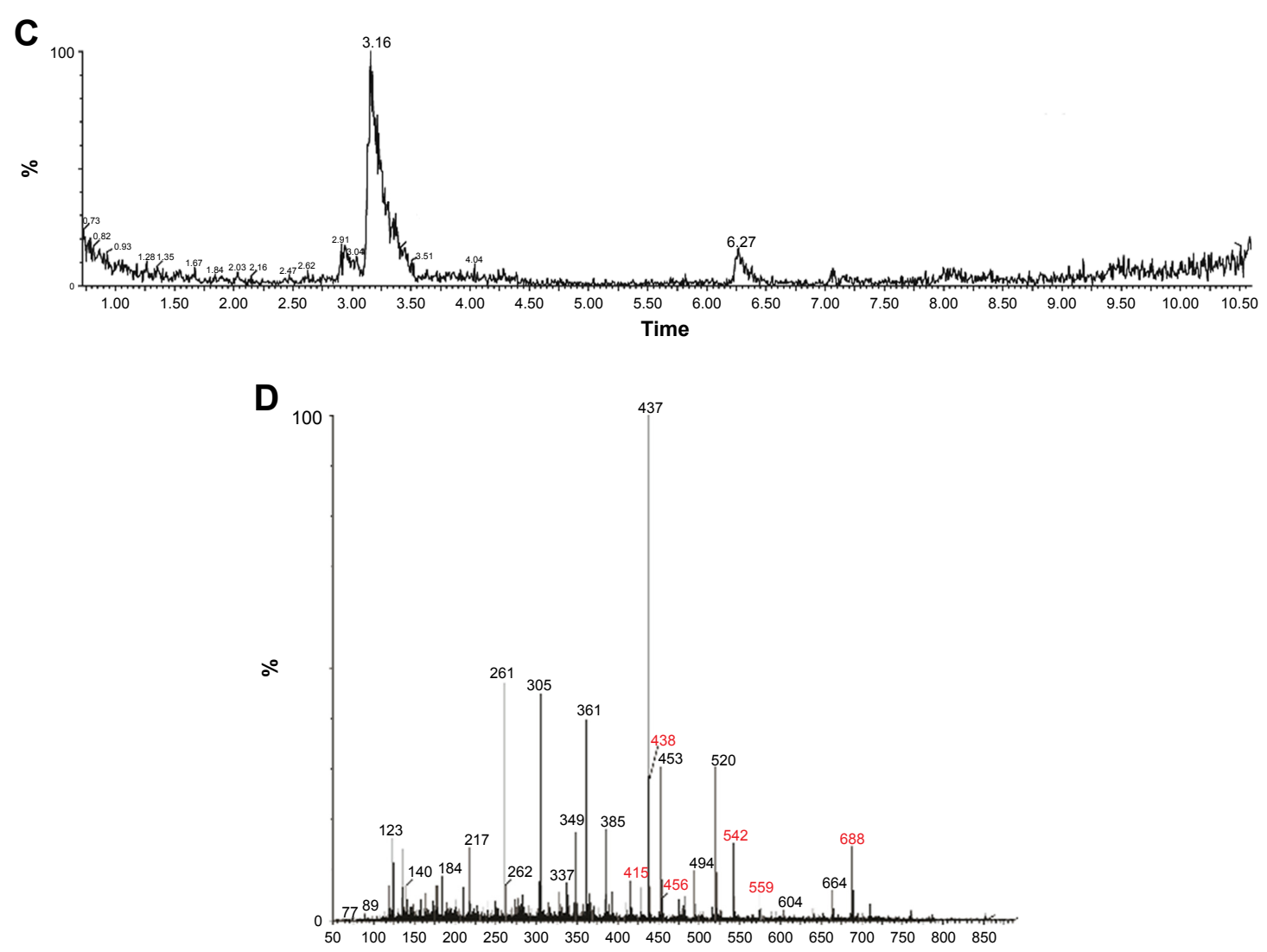

$\mathrm{m} / \mathbf{z}$
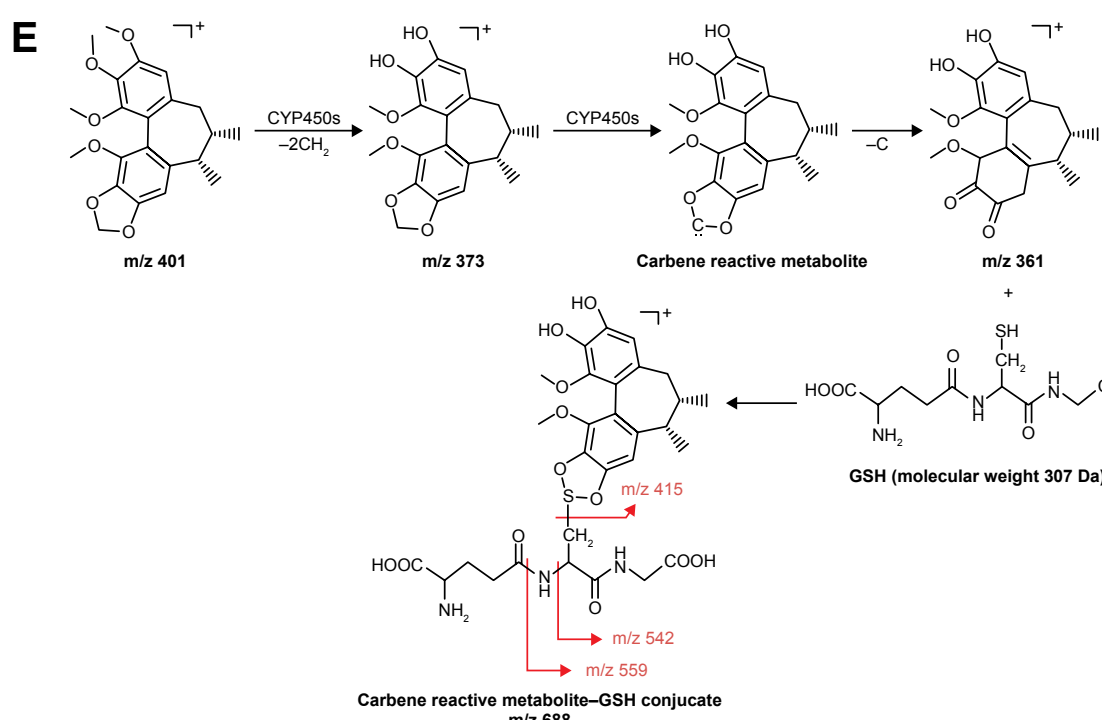

reactive metabolite

$\mathrm{m} / \mathrm{z} 361$

$\mathrm{m} / \mathbf{z} 688$

Figure 2 Characterization of the GSH-carbene reactive metabolite conjugate of Sch B in human liver microsomes.

Notes: (A) Extracted ion chromatograms from incubations without Sch B. (B) Extracted ion chromatograms from incubations in the presence of Sch B and ABT (a known CYP450 inhibitor). (C) Extracted ion chromatograms from incubations in the presence of Sch B alone. (D) The MS/MS of the ion at $\mathrm{m} / \mathrm{z} 688$ displayed the product ions of 599 (-129 Da, pyroglutamate), $542(-146 \mathrm{Da}), 438(-250 \mathrm{Da})$, and $415(-273 \mathrm{Da})$. (E) The proposed pathway of carbene reactive metabolite formation from Sch B and related fragmentation pattern in MS/MS.

Abbreviations: Sch B, schisandrinB; GSH, glutathione; ABT, I-aminobenzotriazolea; MS/MS, tandem mass spectrometery; CYP450, cytochrome P450.

As the protonated molecule $[\mathrm{M}+\mathrm{H}]^{+}$, retention time, and the product ions of the GSH conjugate in mice and human liver microsomes were similar, only the data on human liver microsomes are provided here. The formation of GSH conjugate was CYP dependent, as shown by the representative extracted ion chromatograms from human liver microsomal incubations in the presence of CYP450 inhibitor ABT (Figure 2A and C). LC-MS/MS analysis of the peak responsible for GSH conjugate displayed a protonated molecule $[\mathrm{M}+\mathrm{H}]^{+}$at $\mathrm{m} / \mathrm{z} 688,287 \mathrm{Da}$ higher than that 
of the parent drug, which indicated that Sch B first loses $2\left[-\mathrm{CH}_{2}\right]$, followed by conjugation with one molecule of GSH (Figure 2D and E). Besides, the MS/MS of the ion at $\mathrm{m} / \mathrm{z}$ 688 displayed the product ions of 599 (-129 Da, pyroglutamate), 542 (-146 Da), 438 (-250 Da), and 415 (-273 Da) (Figure 2D), which were thought to be the typical fragment losses of GSH conjugate. Taken together, the structure of GSH conjugate observed in Figure 2C was proposed as the Sch B metabolite and GSH conjugate. The abovementioned data suggested that the CYP450-mediated oxidative metabolism of Sch B produces carbene reactive metabolite.

\section{The carbene reactive metabolite activation of Nrf2 pathway via interacting with Keap I}

Under quiescent conditions, Nrf2 is anchored in the cytoplasm through binding to Keap1, which in turn facilitates the ubiquitination and subsequent proteolysis of Nrf2. Thus, the compound potentially interacting with Keap1 may activate Nrf2 pathway. The theoretical binding mode of carbene reactive metabolite in the binding site of the Keap 1 is shown in Figure 3A. Carbene adopted a compact conformation to bind inside of the pocket of Keap1. In addition, the carbene

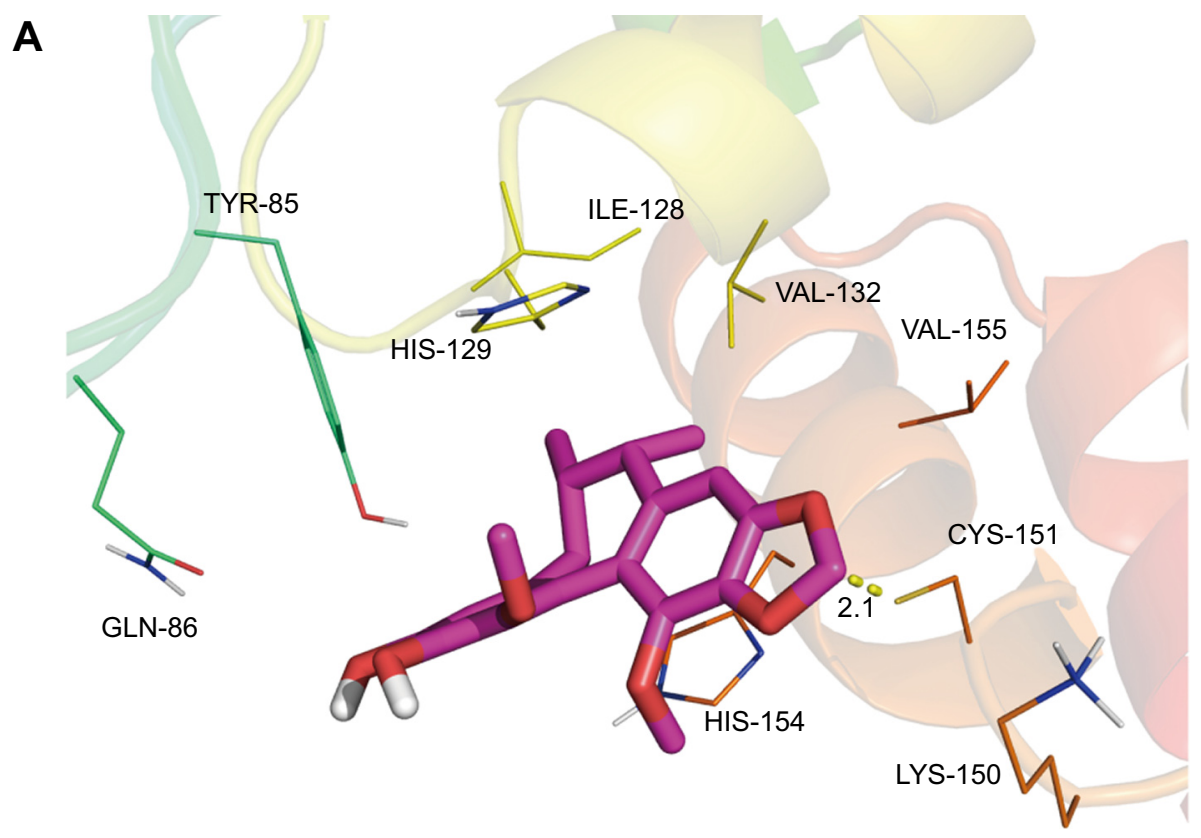

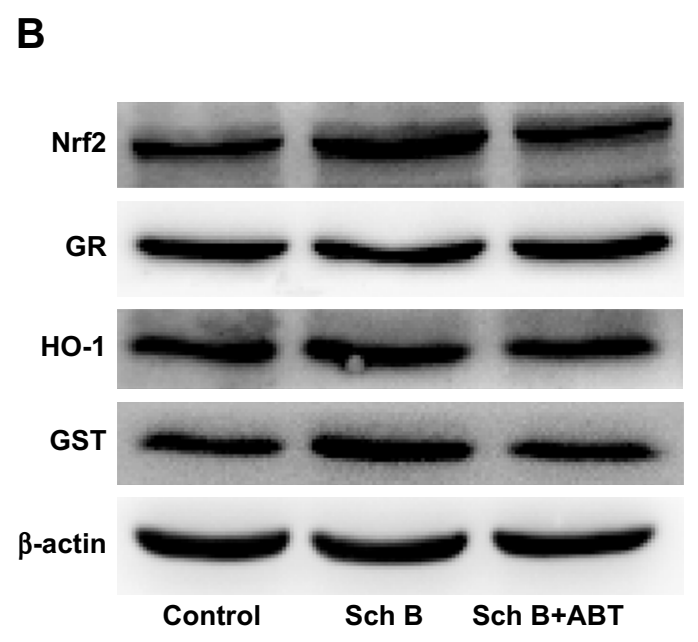

Figure 3 Evidence for SchB elicits the Keap I-Nrf2 defense system via its carbene reactive metabolite.

Notes: (A) Molecular docking of carbene reactive metabolite to Keapl. (B) Sch B (5 $\mu$ M) upregulated the expression of Nrf2 and its downstream detoxification gene of GST, while ABT (a known CYP450 inhibitor, $0.5 \mathrm{mM}$ ) suppressed that activation after 48 -hour incubation in HepG-2 cells. $P<0.01$ vs control group, ${ }^{* * P}<0.0 \mathrm{I}$ vs Sch $B$ group. Abbreviations: Sch B, schisandrin B; ABT, I-aminobenzotriazolea.
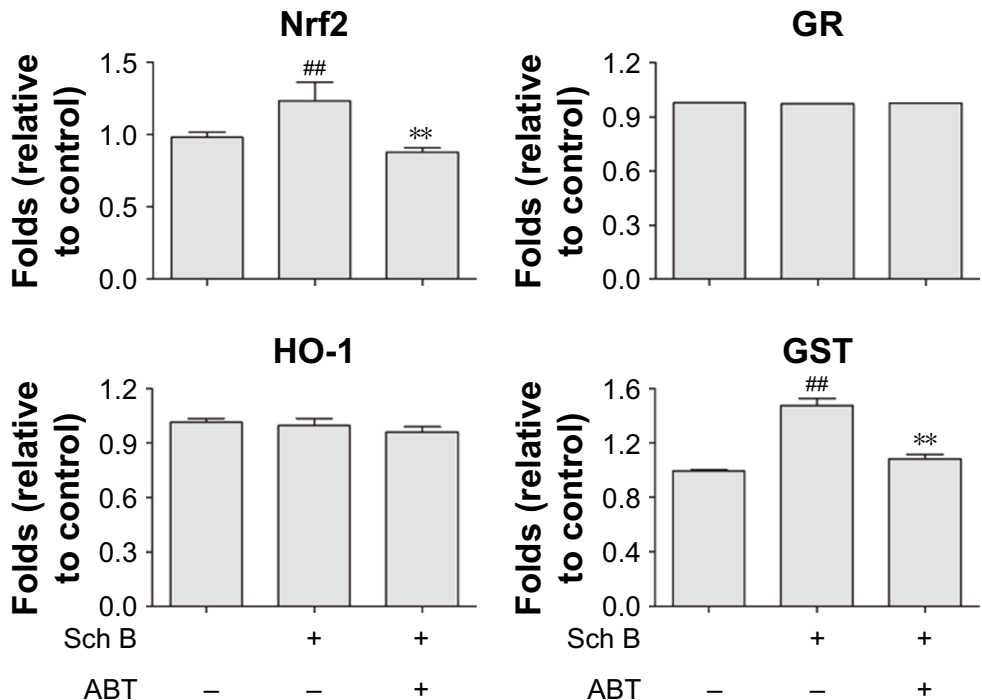
was located at the hydrophobic pocket, surrounded by the residues Ile-128, Val-132, Val-155, and Cys-151, thus forming a stable hydrophobic binding. Detailed analysis showed that the 1,3-benzodioxole group of carbene formed $\pi-\pi$ stacking interaction with the residue His 154. Importantly, the key carbon atom between the two oxygen atoms in the 1,3benzodioxole group of carbene orients to the residue Cys-151 (bond distance: $2.1 \AA$ ) and may form the key interaction with the residue Cys-151. All these interactions helped carbene to anchor in the binding site of the Keap1.

The effects of ABT on the ability of Sch B to activate the Nrf2 signal pathway were further investigated in HepG-2 cells. As shown in Figure 3B, Sch B $(5 \mu \mathrm{M})$ upregulated the expression of Nrf2 and its downstream detoxification gene of GST after 48-hour incubation in HepG-2 cells. However, the combined use of ABT suppressed the abovementioned activation. Besides, no changes were observed in the HO-1 and GR protein expression in all groups.

\section{Carbene reactive metabolite modified peptides from human microsomal proteins}

Shotgun proteomics combining two MS-compatible solubilization approaches was applied to evaluate whether carbene reactive metabolite could covalently modify macromolecules. Briefly, a total of 1,107 and 1,113 proteins were detected in Control and Sch B sample, respectively. Besides, the peptides with the addition of carbene reactive metabolite $(+360)$ to cysteine residues were searched in Protein Pilot database. After subtracting the same peptides searched in control group, only five modified peptides were identified (Table 1). The sequences and monoisotopic elemental masses of these peptides, whose mass accuracy was less than 20 ppm, are shown in Table 1. In addition, each modified peptide identified by the database search was supported by the fragmentation pattern in MS/MS (Figure 4).

\section{The cytotoxicity of carbene reactive metabolite on HepG-2 cells}

To determine whether the carbene reactive metabolite of Sch B has cytotoxicity effects, HepG-2 cells were incubated with CYP450 inducer, inhibitor, and GSH in addition to Sch B. As shown in Figure 5A, Sch B (5-200 $\mu \mathrm{M})$ inhibited the growth and increased the LDH leakage of HepG-2 cells with $\mathrm{LD}_{50}$ at $63 \mu \mathrm{M}$. The addition of ABT (CYP450 inhibitor, $0.5 \mathrm{mM}$ ) and GSH (reactive metabolite trapping agent, $5 \mathrm{mM}$ ) significantly ameliorated the cell viability and LDH leakage $(P<0.05)$ as reflected by increasing $\operatorname{Sch} \mathrm{B} \mathrm{LD}_{50}$ value

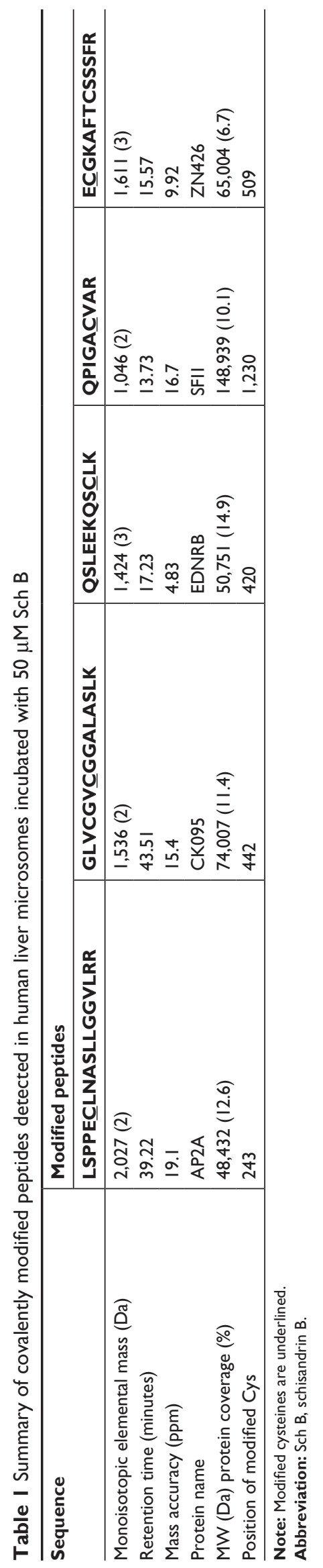



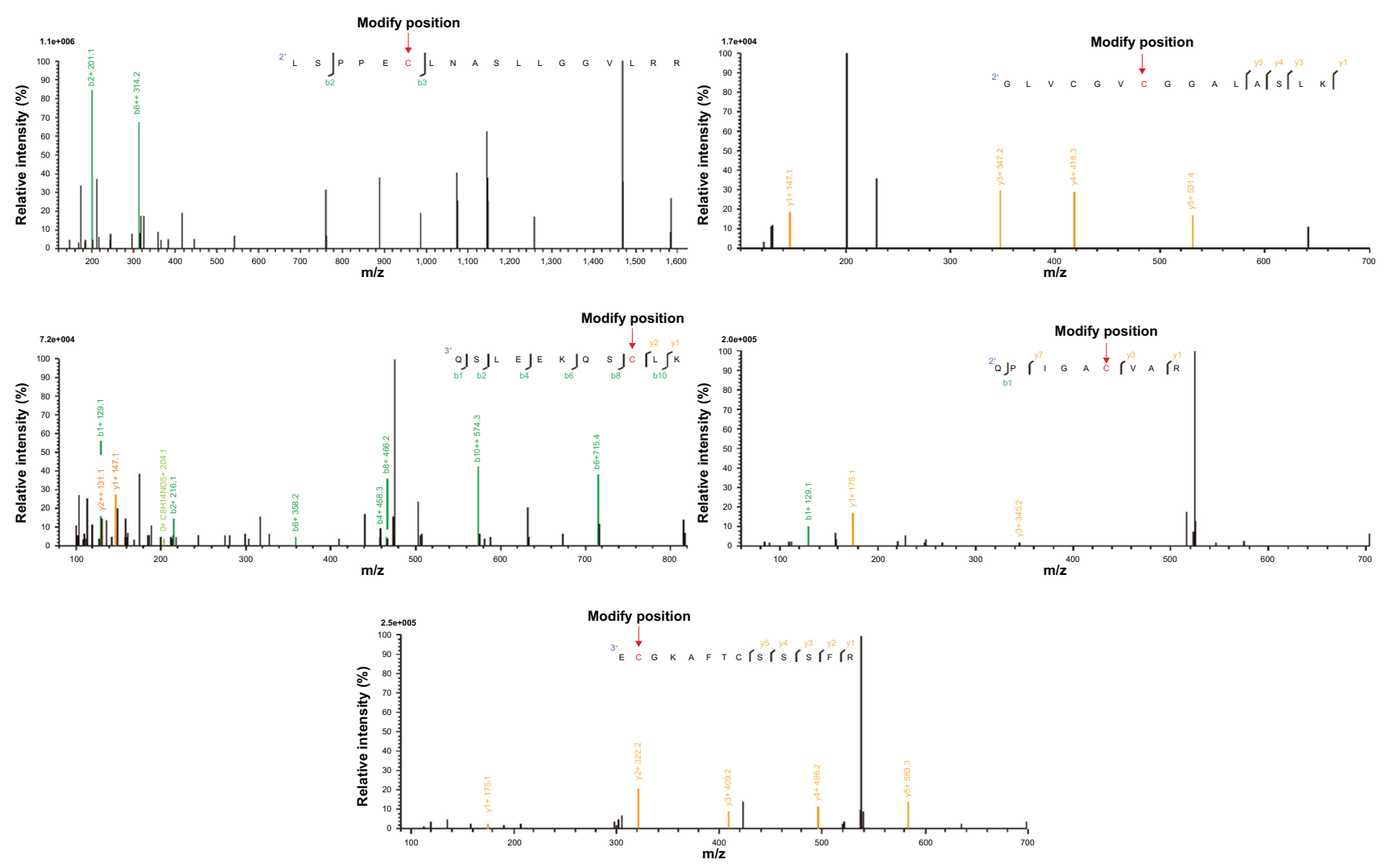

Figure 4 Fragment ion spectra and proposed main fragmentation route for peptides modified by the carbene reactive metabolite of Sch B. Abbreviation: Sch B, schisandrin B.

to $>200 \mu \mathrm{M}$. In contrast, Phen (CYP450 inducer, $20 \mu \mathrm{M})$ significantly aggravated the cytotoxic effect of Sch B on HepG-2 cells $(P<0.01)$ by reducing the $\mathrm{LD}_{50}$ to $21 \mu \mathrm{M}$. In conclusion, the cytotoxic effect of Sch B on HepG-2 cells is associated with elevated CYP450 activity, which may result in carbene reactive metabolite generation.

\section{Long-term administration of Sch B induced mild mice liver injury, Nrf2 activation, and CYP450 activity upregulation}

Male KM mice treated with a series of doses of Sch B (25.0, 50.0 , and $100.0 \mathrm{mg} / \mathrm{kg}$ ) for 21 days were used to determine the influence of Sch B on mouse liver function. Treatment with Sch B resulted in a significant increase in aminotransferase activity in a dose-dependent manner $(P<0.05)$ (Table 2). Meanwhile, centrilobular hepatocellular infiltration of lymphocytes was clearly evident in $100 \mathrm{mg} / \mathrm{kg}$ Sch Binjured livers as demonstrated by histopathological analysis of H\&E-stained liver sections (Figure 5B). Furthermore, very limited positive TUNEL cell was detected in $100 \mathrm{mg} / \mathrm{kg} \mathrm{Sch}$ B-treated liver by immunofluorescence staining (Figure 5C).
After male KM mice were treated with a series of doses of Sch B (25.0, 50.0, and $100.0 \mathrm{mg} / \mathrm{kg}$ ) for 21 days, all of the main five CYP450s, (CYP1A2/2C9/2D6/2E1/3A4) activities in livers of mice from Sch B-treated groups considerably increased in a dose-dependent manner (Figure 6A). In addition, Western blotting results demonstrated that Sch B $(25.0-100.0 \mathrm{mg} / \mathrm{kg})$ upregulated the Nrf2 expression in a dose-dependent manner. Besides, the protein expression of antioxidant and detoxification genes of NQO-1 and GST in Nrf2 pathway also showed a dose-dependent increase (Figure 6B). Meanwhile, the upregulation of antioxidant factor GSH (Table 2) in the liver was also observed in Sch B-treated groups.

\section{Discussion}

The aim of this study was to explore the reactive metabolite structure and function of Sch B. The obtained results showed that CYP450s could mediate Sch B to produce carbene reactive metabolite, characterized by electrophilicity, which could activate Nrf2 signal pathway by modifying Keap1. Besides, carbene could modify phaseolin polypeptide and induce cytotoxicity under the high activity of CYP450s. 
A

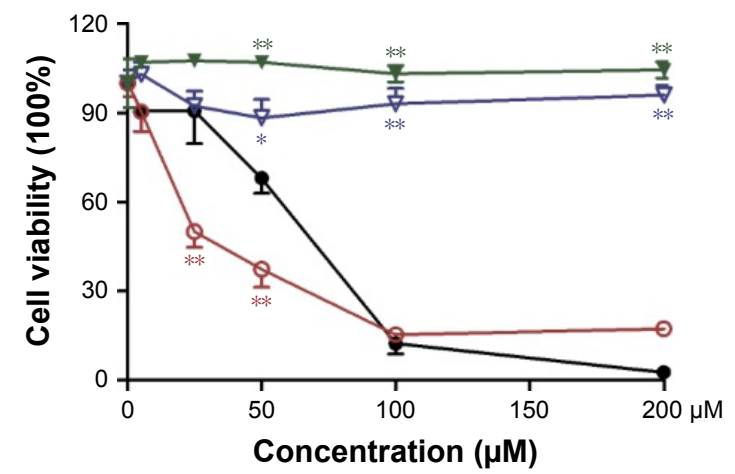

\begin{tabular}{|l|c|c|c|c|}
\hline Group & Sch B & Sch B + ABT & Sch B + Phen & Sch B + GSH \\
\hline $\mathrm{LD}_{50}(\mu \mathrm{M})$ & 63 & $>200$ & 21 & $>200$ \\
\hline
\end{tabular}

B

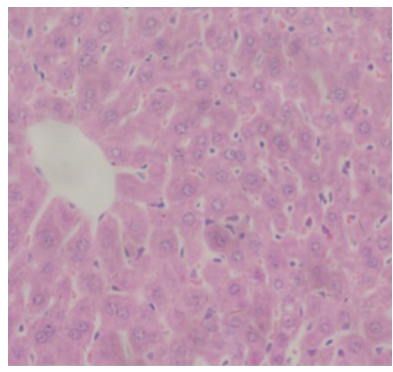

C

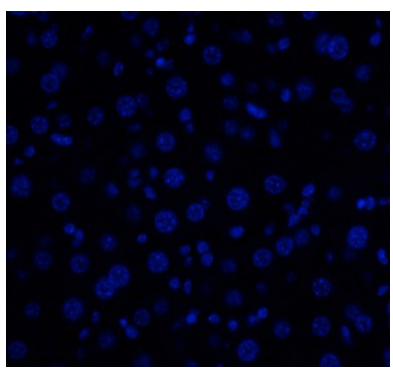

Control
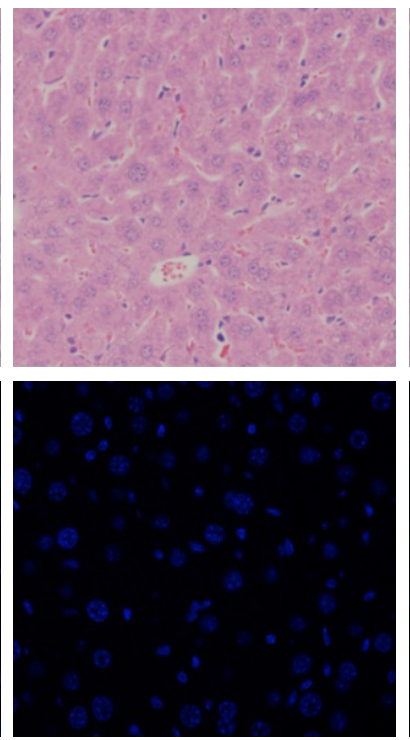

$25 \mathrm{mg} / \mathrm{kg}$

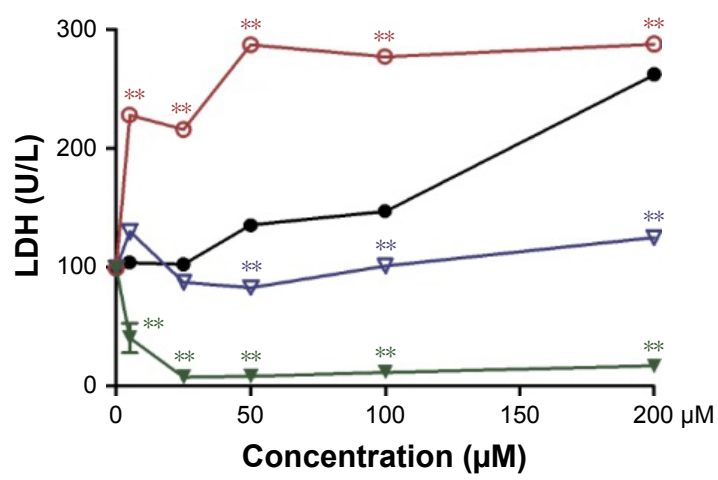

$\bullet$ Sch B $\rightarrow$ Sch B-ABT $\bullet$ Sch B-Phen $\rightarrow$ Sch B-GSH


$50 \mathrm{mg} / \mathrm{kg}$

Sch B

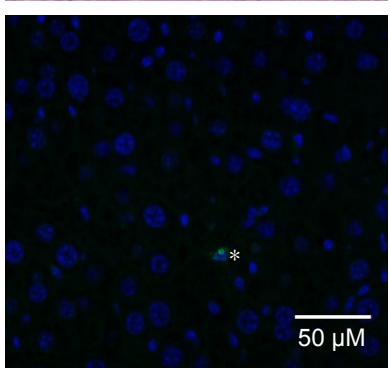

$100 \mathrm{mg} / \mathrm{kg}$

Figure 5 Effects of Sch B on HepG-2 viability and mice liver function

Notes: (A) The influence of GSH (reactive metabolite trapping agent), ABT (a known CYP450 inhibitor), and Phen (a known CYP450 inducer) on the cytoxicity of Sch B in HepG-2 cells as revealed by the cell viability, LDH leakage, and LD $_{50^{*}}(\mathbf{B}, \mathbf{C})$ Effects of 21 -day administration of Sch B on the mice liver functions as revealed by the histopathological analysis of H\&E-stained liver sections (B) and by the TUNEL immunofluorescence histochemical staining (C). Notes: Black arrow indicates the infiltration of lymphocytes; $*$ indicates positive cells stained by TUNEL $(n=6$, mean $\pm S D$ ). $* P<0.05, * * P<0.0$ I vs control group.

Abbreviations: ABT, I-aminobenzotriazolea; Phen, Phenobarbital sodium; Sch B, Schisandrin B; GSH, glutathione; LDH, actate dehydrogenase.

Yet long-term animal experiments reflected that Sch B causes no significant hepatotoxicity in mice.

CYP450s may metabolize drugs to electrophilic reactive metabolites, which are characterized by free radicals, causing mitochondria damage and cell necrosis. Lammert et al have statistically analyzed 207 most commonly used oral drugs and found that $62 \%-69 \%$ of these medications could lead to hepatotoxicity through the formation of reactive metabolites. ${ }^{21}$ Thus, monitoring reactive metabolites in the early stage of drug development is of great significance.

Table 2 Effects of Sch B on the activities of ALT, AST, and ALP in mouse serum

\begin{tabular}{|c|c|c|c|c|}
\hline \multirow[t]{2}{*}{ Test index } & \multirow[t]{2}{*}{ Control } & \multicolumn{3}{|l|}{ Sch B (mg/kg) } \\
\hline & & 50 & 100 & 200 \\
\hline $\mathrm{ALT}(\mathrm{U} / \mathrm{L})$ & $34.50 \pm 4.51$ & $46.67 \pm 7.53 *$ & $57.60 \pm 9.53 * *$ & $83.33 \pm 8.6 I^{* *}$ \\
\hline AST (U/L) & $105.67 \pm 9.79$ & $222.80 \pm 49.36 * *$ & $184.20 \pm 72.75^{*}$ & $167.60 \pm 24.64 *$ \\
\hline ALP (U/L) & $214.00 \pm 22.11$ & $191.00 \pm 27.78$ & $157.17 \pm 18.69 * *$ & $|33.33 \pm 29.5| * *$ \\
\hline GSH ( $\mu g / m g$ protein) & $86.62 \pm 1.65$ & $90.91 \pm 13.47$ & $100.59 \pm 14.45$ & $125.32 \pm 12.45^{* *}$ \\
\hline
\end{tabular}

Notes: $n=6$, mean $\pm S D ; * P<0.05$, $* * P<0.0$ I vs control group.

Abbreviations: Sch B, schisandrin B; ALT, alanine aminotransferase; AST, aspartate aminotransferase; ALP, alkaline phosphatase; GSH, glutathione. 
A
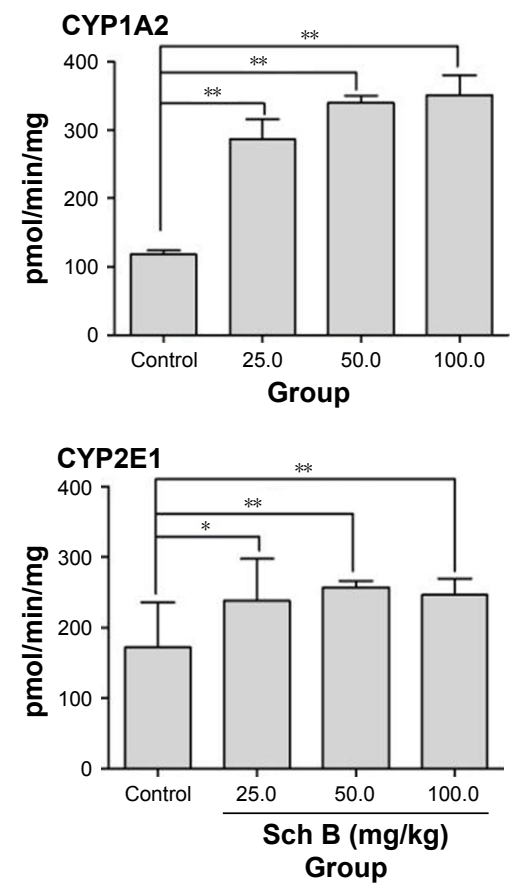

B

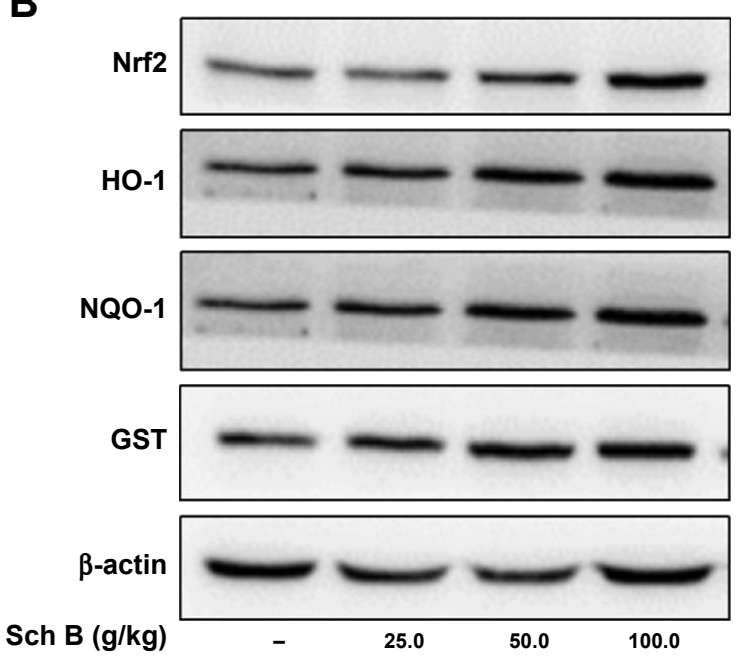

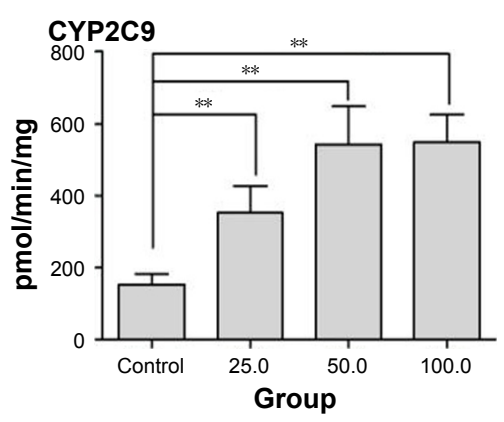
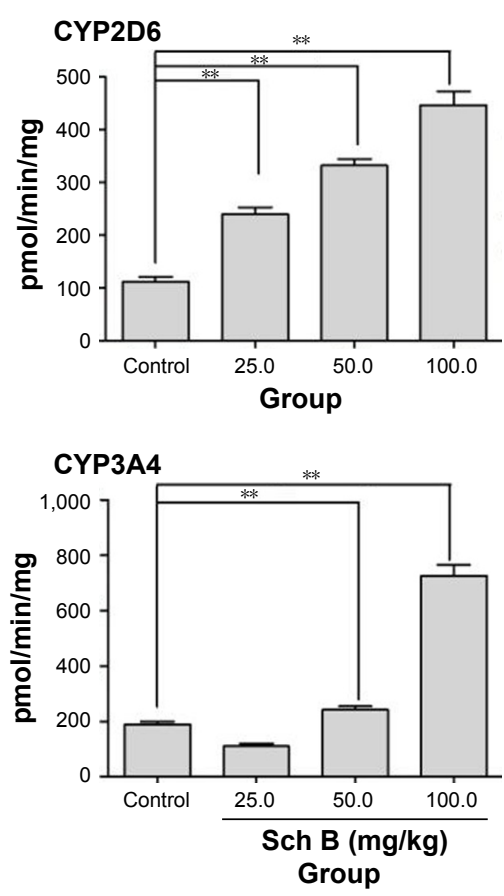
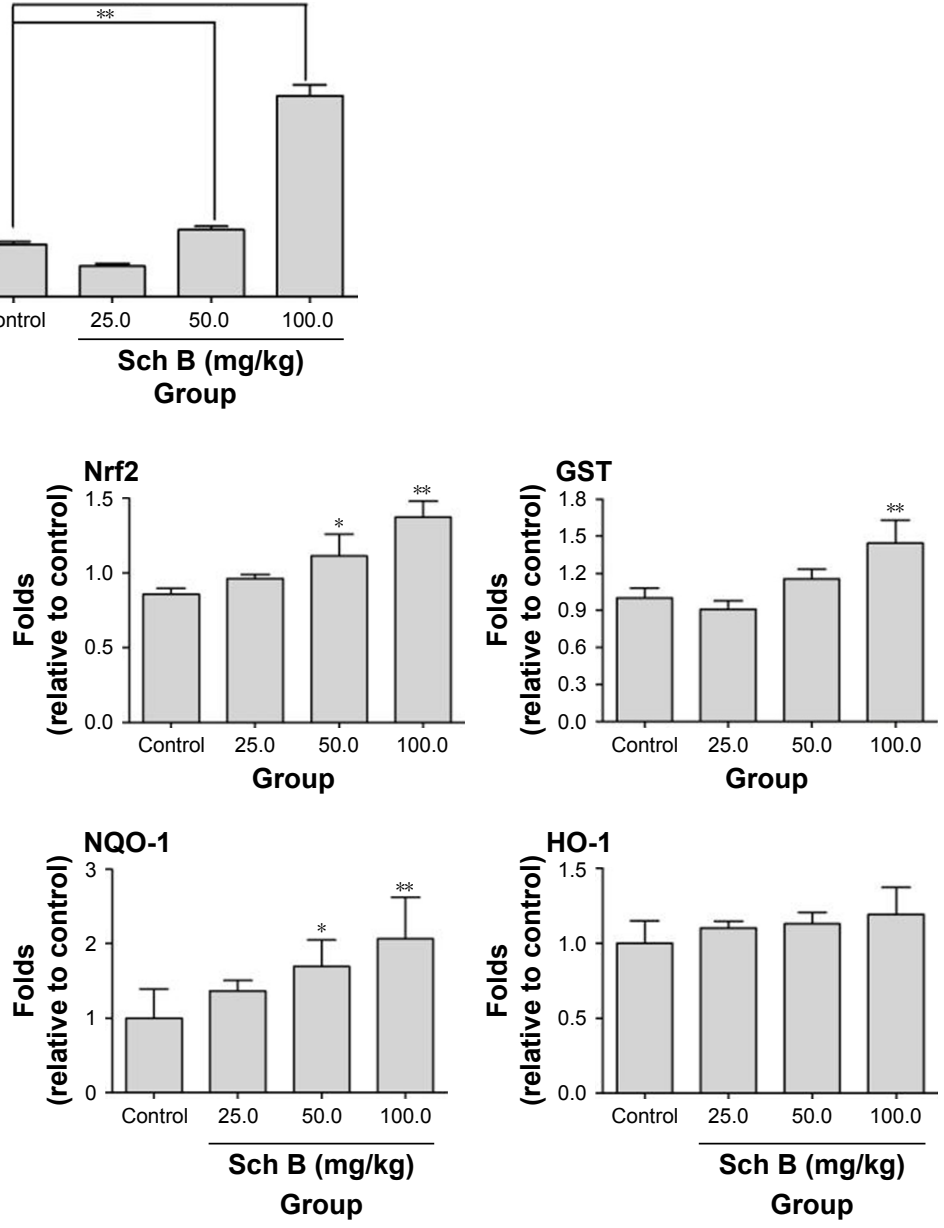

Figure 6 Effects of Sch B on the activity and protein expression of Nrf2 pathway in liver tissue of mice after $2 \mathrm{I}$ days of oral administration (25.0, 50.0, and I00.0 mg/kg). Notes: (A) Cocktail method evaluated the five main CYP450 (CYPIA2/2C9/2D6/2EI/3A4) activities in mouse liver; (B) Western blotting reflected the Nrf2, NQO-I, HO-I, and GST protein expression. $n=6$, mean $\pm S D ; * P<0.05$, ${ }^{* *} P<0.0$ I vs control group. Abbreviations: Sch B, schisandrin B; CYP450, cytochrome P450.

The benzene functional group (Figure 1B) is a common functional group for producing carbene or $o$-benzoquinone active metabolites under the action of CYP450s. ${ }^{13}$ Paroxetine, a commonly used antidepressant, contains this functional group and was shown to induce jaundice, acute hepatitis, and chronic hepatitis. ${ }^{22-24}$ The mechanism of liver injury is mainly related to the $o$-benzoquinone reactive metabolites depleting GSH and binding intracellular macromolecule protein to induce cell stress. ${ }^{25}$ Similarly, the present study confirmed that the benzene functional group of Sch B could produce carbene reactive metabolite, which has the cytotoxicity potential, as reflected by the CYP450 inducer which aggravated Sch B cytotoxicity $\left(\mathrm{LD}_{50}=21 \mu \mathrm{M}\right)$. Also, the mechanism of carbene-induced cytotoxicity was shown to be associated with GSH depletion, which was verified by supplementing with GSH that alleviated Sch B cytotoxicity (with $\mathrm{LD}_{50}$ from 63 to $>200 \mu \mathrm{M}$ ).

Unlike the results from the HepG-2 cell test, although the activity of CYP450s in mice liver was upregulated 3 weeks after oral administration of Sch B, mild hepatotoxicity was 
observed only in the highest dose $(100 \mathrm{mg} / \mathrm{kg})$ group. This might be related to the upregulation of Nrf2 downstream protein such as GST (Figure 6B), which accelerated the clearance of reactive metabolite carbene. Taken together, the influence of Sch B on mice liver function possibly relies on the combined effects of Nrf2 activation and CYP activity induction. As the highest dose and duration of Sch B applied in the present study are higher and longer than those reported previously ( $80 \mathrm{mg} / \mathrm{kg}, 3$ days), ${ }^{3,9,10,18,19}$ we concluded that carbene may have less harmful effect on mice liver. It is necessary to point out that this study only evaluated the safety when Sch B was administered alone (25-100 mg/ $\mathrm{kg}$ ) in mice. However, its effect in combination with other drugs, especially the safety of the combination with the CYP450 inducer, needs to be further explored. In addition, the liver microsomal incubation experiment revealed that carbene could modify polypeptide, whereas the ability of Sch B to induce idiosyncratic liver injury still needs to be verified.

Nrf2/ARE is a defensive transduction pathway that has been shown to be resistant to internal and external oxidation, as well as to chemical stimulation. Under physiological conditions, Nrf2 binds to Keap1 in the cytoplasm and is in an inactive and easily degraded state. Yet the reactive metabolites are electrophilic and could covalently bind cysteine residues in Keap1, change the conformation of Keap1, and then release Nrf2 into the nucleus. It is known that the hepatotoxicity of paracetamol is mainly mediated by its reactive metabolite $N$-acetyl- $p$-benzoquinoneimine. ${ }^{26,27}$ Moreover, Copple et al have confirmed that the $N$-acetyl- $p$ benzoquinoneimine reactive metabolite could also activate the Nrf2 signaling pathway by binding cysteine residues in Keap $1 .{ }^{28}$ Besides, the present study also demonstrated that carbene has the potential to covalently bind cysteine residues in Keap1, and then activate the Nrf2 pathway by reducing the stability of keap1/Nrf2. The results were consistent with previous studies which suggested that reactive oxygen species produced by CYP-catalyzed metabolism are involved in the Nrf2 activation..$^{5,11,12}$ Nevertheless, the results of molecular docking in the present study only provided evidence for carbene modifying Keap1. Further experiments such as incubating Sch B reactive metabolite with recombination Keap1 for detecting their conjugate are necessary to confirm these findings. Schisandrin A and schisandrol B, two lignan constituents of $S$. chinensis, have been reported to ameliorate hepatotoxicity or inflammation via activating the Nrf2 pathway. ${ }^{29,30}$ Interestingly, benzodioxole is a constituent of their structure; therefore, whether the reactive metabolites of benzodioxole are responsible for Nrf2 activation needs exploration in the future studies.
Drug-drug interactions may result from the ability of various chemicals to modulate the activity of CYP450 enzymes. The influence of Sch B on the CYP450 activity has been reported previously. Li et al observed that an oral administration of Sch B (2-16 mg/kg) for three consecutive days may significantly inhibit rat hepatic microsomal CYP3A activity in a dose-dependent manner, with a $K_{\mathrm{i}}$ value of $16.64 \mathrm{mg} / \mathrm{kg} .{ }^{31}$ Besides, they also demonstrated that Sch B could inhibit the CYP3A activity with $\mathrm{IC}_{50}$ value at $5.51 \mu \mathrm{M}^{32}$ in rat liver microsomes. Similarly, Qin et al reported that one single dose of Sch B $(0.024 \mathrm{mM} / \mathrm{kg})$ could increase the tacrolimus bioavailability in rat via inhibiting the $\mathrm{P}$-gp-mediated efflux and CYP3A-mediated metabolism. ${ }^{33}$ However, contrary to previous studies, the present study showed that oral Sch B (25.0-100.0 mg/kg) for 21 days considerably increased mice liver CYP450 (CYP1A2/2C9/2D6/2E1/3A4) activities (Figure 6A). S. chinensis produced similar effects on CYP450s. Chen et al observed that the inhibitory effect of $S$. chinensis aqueous extract on the CYP3A activity was converted to inductive effect after 6-day gavage. ${ }^{34}$ In the same study, Sch B $(0.1 \mu \mathrm{M})$ was demonstrated to significantly increase the expression of CYP3A1 mRNA in rat primary hepatocytes. ${ }^{34}$ Similarly, Wang et al proved that multiple administrations of $S$. chinensis aqueous extract $(1.5 \mathrm{~g} / \mathrm{kg}$, 7 days) and alcoholic extract ( $1.5 \mathrm{~g} / \mathrm{kg}, 7$ days $)$ increased the activities, mRNA, and protein expressions of CYP2E1 and CYP3A1/2 in rats. ${ }^{35}$ Taken together, the abovementioned results, it seemed that Sch B also has dual effects on hepatic CYP3A activities, as short-term or one single dose could inhibit the CYP3A activity, while long-term administration shows the upregulation of CYP3A activity. In fact, due to the dose, duration, and species differences from the previous study, further studies should be conducted to demonstrate the dual effects of Sch B on hepatic CYP450s. In addition, as Sch B exhibits high induction effects on CYP450s, more attention should be paid on long-term clinical use of this herbal medicine containing Sch B as it may lead to therapeutic failure.

\section{Conclusion}

The present study provides full information on the structure and function of carbene reactive metabolite of Sch B. The carbene is characterized by electrophilicity, which not only activates Nrf2 signal pathway by modifying Keap1 but can also modify phaseolin polypeptide, and is harmless to mice liver. Besides, long-term administration of Sch B showed the induction effects on CYP450 activity, which is contrary to previous reports, and further studies are needed to confirm whether Sch B has dual effects on hepatic CYP450s. 


\section{Acknowledgments}

This study was funded by Chongqing Research Program Basic Research and Frontier Technology (No.cstc2017jcyjAX0137,-cstc2018jcyjAX0158), China Postdoctoral Science Foundation (2016M602641), Postdoctoral Foundation of Southwest University (102060-20750902), and National Natural Science Foundation of China (NSFC) (NSFC-81402393, -81572678, -81873034 and 21602180).

\section{Author contributions}

Shan Feng, Xiaoyu Xu, and Huifeng Zhu designed the study. Shan Feng, Bingxun Qiu, Ke Liu, and Li Zou performed the study. Shan Feng, Huifeng Zhu, and Xiaoyu Xu wrote the manuscript. Xiaoyu Xu and Huifeng Zhu were the principal investigators and corresponding authors. All authors contributed to data analysis, drafting and revising the article, gave final approval of the version to be published, and agree to be accountable for all aspects of the work.

\section{Disclosure}

The authors report no conflicts of interest in this work.

\section{References}

1. Fan X, Chen P, Jiang Y, et al. Therapeutic efficacy of Wuzhi tablet (Schisandra sphenanthera Extract) on acetaminophen-induced hepatotoxicity through a mechanism distinct from $\mathrm{N}$-acetylcysteine. Drug Metab Dispos. 2015;43(3):317-324.

2. Lai Q, Wei J, Mahmoodurrahman M, et al. Pharmacokinetic and nephroprotective benefits of using Schisandra chinensis extracts in a cyclosporine A-based immune-suppressive regime. Drug Des Devel Ther. 2015;9:4997-5018.

3. Ba Q, Cui C, Wen L, et al. Schisandrin B shows neuroprotective effect in 6-OHDA-induced Parkinson's disease via inhibiting the negative modulation of miR-34a on Nrf2 pathway. Biomed Pharmacother. 2015;75:165-172.

4. Chun JN, Cho M, So I, Jeon JH. The protective effects of Schisandra chinensis fruit extract and its lignans against cardiovascular disease: a review of the molecular mechanisms. Fitoterapia. 2014;97:224-233.

5. Leong PK, Chiu PY, Chen N, Leung H, Ko KM. Schisandrin B elicits a glutathione antioxidant response and protects against apoptosis via the redox-sensitive ERK/Nrf2 pathway in AML12 hepatocytes. Free Radic Res. 2011;45(4):483-495.

6. Checker R, Patwardhan RS, Sharma D, et al. Schisandrin B exhibits anti-inflammatory activity through modulation of the redox-sensitive transcription factors Nrf2 and NF-кB. Free Radic Biol Med. 2012;53(7): 1421-1430.

7. Dong Q, Hou H, Wu J, Chen Y. The Nrf2-ARE pathway is associated with Schisandrin $b$ attenuating benzo(a)pyrene-Induced HTR cells damages in vitro. Environ Toxicol. 2016;31(11):1439-1449.

8. Lin Q, Qin X, Shi M, et al. Schisandrin B inhibits LPS-induced inflammatory response in human umbilical vein endothelial cells by activating Nrf2. Int Immunopharmacol. 2017;49:142-147.

9. Chen Q, Zhang H, Cao Y, et al. Schisandrin B attenuates $\mathrm{CCl}_{4}$-induced liver fibrosis in rats by regulation of Nrf2-ARE and TGF- $\beta /$ Smad signaling pathways. Drug Des Devel Ther. 2017;11:2179-2191.

10. Jia R, Zhang H, Yang Z, et al. Protective effects of Schisandrin B on cigarette smoke-induced airway injury in mice through Nrf2 pathway. Int Immunopharmacol. 2017;53:11-16.
11. Chen N, Chiu PY, Leung HY, Ko KM. Cytochrome P-450-catalyzed reactive oxygen species production mediates the $(-)$ schisandrin B-induced glutathione and heat shock responses in H9c2 cardiomyocytes. Indian J Pharmacol. 2012;44(2):204-209.

12. Chiu PY, Chen N, Leong PK, Leung HY, Ko KM. Schisandrin B elicits a glutathione antioxidant response and protects against apoptosis via the redox-sensitive ERK/Nrf2 pathway in $\mathrm{H} 9 \mathrm{c} 2$ cells. Mol Cell Biochem. 2011;350(1-2):237-250.

13. Fontana E, Dansette PM, Poli SM. Cytochrome p450 enzymes mechanism based inhibitors: common sub-structures and reactivity. Curr Drug Metab. 2005;6(5):413-451.

14. Trott O, Olson AJ. AutoDock Vina: improving the speed and accuracy of docking with a new scoring function, efficient optimization, and multithreading. J Comput Chem. 2010;31(2):455-461.

15. Morris GM, Huey R, Lindstrom W, et al. AutoDock4 and AutoDockTools4: automated docking with selective receptor flexibility. J Comput Chem. 2009;30(16):2785-2791.

16. Sanner MF. Python: a programming language for software integration and development. J Mol Graph Model. 1999;17(1):57-61.

17. Yang Y, Xiao Q, Humphreys WG, Dongre A, Shu YZ. Identification of human liver microsomal proteins adducted by a reactive metabolite using shotgun proteomics. Chem Res Toxicol. 2014;27(9):1537-1546.

18. Checker R, Patwardhan RS, Sharma D, et al. Schisandrin B exhibits anti-inflammatory activity through modulation of the redox-sensitive

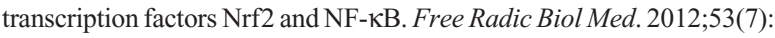
1421-1430.

19. Leong PK, Ko KM. Schisandrin B induces an Nrf2-mediated thioredoxin expression and suppresses the activation of inflammasome in vitro and in vivo. Biofactors. 2015;41(5):314-323.

20. Yan J, He X, Feng S, et al. Up-regulation on cytochromes P450 in rat mediated by total alkaloid extract from Corydalis yanhusuo. BMC Complement Altern Med. 2014;14:306.

21. Lammert C, Bjornsson E, Niklasson A, Chalasani N. Oral medications with significant hepatic metabolism at higher risk for hepatic adverse events. Hepatology. 2010;51(2):615-620.

22. Azaz-Livshits T, Hershko A, Ben-Chetrit E. Paroxetine associated hepatotoxicity: a report of 3 cases and a review of the literature. Pharmacopsychiatry. 2002;35(3):112-115.

23. Odeh M, Misselevech I, Boss JH, Oliven A. Severe hepatotoxicity with jaundice associated with paroxetine. Am J Gastroenterol. 2001; 96(8):2494-2496.

24. Helmchen C, Boerner RJ, Meyendorf R, Hegerl U. Reversible hepatotoxicity of paroxetine in a patient with major depression. Pharmacopsychiatry. 1996;29(6):223-226.

25. Feng S, He X. Mechanism-based inhibition of CYP450: an indicator of drug-induced hepatotoxicity. Curr Drug Metab. 2013;14(9): 921-945.

26. Zhou S, Chan E, Duan W, Huang M, Chen Y-Z, et al. Drug Bioactivation Covalent Binding to Target Proteins and Toxicity Relevance. Drug Metab Rev. 2005;37(1):41-213.

27. Kaplowitz N. Acetaminophen hepatoxicity: what do we know, what don't we know, and what do we do next? Hepatology. 2004;40(1): 23-26.

28. Copple IM, Goldring CE, Jenkins RE, et al. The hepatotoxic metabolite of acetaminophen directly activates the Keap1-Nrf2 cell defense system. Hepatology. 2008;48(4):1292-1301.

29. Jiang YM, Wang Y, Tan HS, et al. Schisandrol B protects against acetaminophen-induced acute hepatotoxicity in mice via activation of the NRF2/ARE signaling pathway. Acta Pharmacol Sin. 2016;37(3): 382-389.

30. Kwon DH, Cha HJ, Choi EO, et al. Schisandrin A suppresses lipopolysaccharide-induced inflammation and oxidative stress in RAW 264.7 macrophages by suppressing the NF- $\mathrm{BB}$, MAPKs and PI3K/Akt pathways and activating $\mathrm{Nrf2} / \mathrm{HO}-1$ signaling. Int J Mol Med. 2018; 41(1):264-274.

31. Li WL, Xin HW, Su MW, Xiong L, W1 L, Mw S. Inhibitory effects of schisandrin A and schisandrin B on CYP3A activity. Methods Find Exp Clin Pharmacol. 2010;32(3):163-169. 
32. Li WL, Xin HW, Yu AR, Wu XC, Wl L, Ar Y. In vivo effect of Schisandrin B on cytochrome P450 enzyme activity. Phytomedicine. 2013;20(8-9):760-765.

33. Qin XL, Chen X, Wang Y, et al. In vivo to in vitro effects of six bioactive lignans of Wuzhi tablet (Schisandra sphenanthera extract) on the CYP3A/P-glycoprotein-mediated absorption and metabolism of tacrolimus. Drug Metab Dispos. 2014;42(1):193-199.

34. Chen Q, Wu YJ, Cheng NN, Li YL, Wang YM. Dual effects of extract of Schisandra chinensis Baill on rat hepatic CYP3A. Yao Xue Xиe Bao. 2010;45(9):1194-1198.
35. Wang B, Yang S, Hu J, Li Y. Multifaceted interaction of the traditional Chinese medicinal herb Schisandra chinensis with cytochrome P450-mediated drug metabolism in rats. J Ethnopharmacol. 2014; 155(3):1473-1482.

36. AAALAC International [webpage on the Internet]. What is AAALAC? Available from: https://www.aaalac.org/about/index.cfm. Accessed October 25, 2018.

37. American University [webpage on the Internet]. About the IACUC. Available from: https://www.american.edu/research/about-iacuc.cfm. Accessed October 30, 2018.

\section{Publish your work in this journal}

Drug Design, Development and Therapy is an international, peerreviewed open-access journal that spans the spectrum of drug design and development through to clinical applications. Clinical outcomes, patient safety, and programs for the development and effective, safe, and sustained use of medicines are the features of the journal, which has also been accepted for indexing on PubMed Central. The manuscript management system is completely online and includes a very quick and fair peer-review system, which is all easy to use. Visit http://www.dovepress.com/testimonials.php to read real quotes from published authors.

Submit your manuscript here: http://www.dovepress.com/drug-design-development-and-therapy-journal 